\title{
Association of FKBP5 polymorphisms with patient susceptibility to coronary artery disease comorbid with depression
}

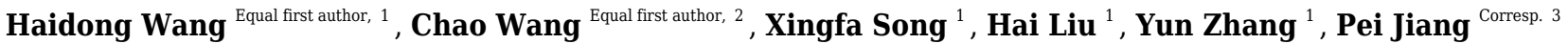 \\ ${ }^{1}$ Department of Pharmacy, The Affiliated Lianyungang Hospital of Xuzhou Medical University/The First People's Hospital of Lianyungang, Lianyungang, \\ Jiangsu, China \\ 2 Department of Pharmacy, Hainan General Hospital, Haikou, Hainan, China \\ 3 Department of Pharmacy, Affiliated Jining First People's Hospital of Jining Medical University, Jining Medical University, Jining, Shandong, China \\ Corresponding Author: Pei Jiang \\ Email address: jiangpeicsu@sina.com
}

Background : Coronary artery disease (CAD) and depression cause great burden to society and frequently co-occur. The exact mechanisms of this comorbidity are unclear. FK506-binding protein 51 (FKBP51) is correlated with cardiovascular disease and depression. The aim of this study was to determine the role of the seven single nucleotide polymorphisms (SNPs) of FKBP5 that code FKBP51, namely, rs1360780 (C>T), rs2817032 $(T>C), r s 2817035(G>A), r s 9296158(G>A), r s 9470079(G>A), r s 4713902(T>C)$, and rs3800373 (C>T) in a patient's susceptibility to comorbid CAD and depression. Methods: We enrolled 271 Northern Chinese Han patients with CAD, including 123 patients with depression and 147 patients without depression. We also included 113 healthy controls that match the patients' sex and age. Genomic DNA from whole blood was extracted, and seven SNPs were assessed using MassArray method. Patient Health Questionnaire-9 was applied to access the depression. Results: The GA genotype for rs9470079 was associated with a significantly decreased risk of CAD (odds ratio $=0.506,95 \%$ confidence interval $=$ $0.316-0.810, P=0.005$ ) when the GG genotype was used as reference. A statistically significant difference was observed among females but not among males in the rs9470079 genotype and allele frequency. Patients with CAD were further divided into CAD+D and CAD-D groups according to the presence of comorbid depression and were compared with the controls. Significant differences were found regarding the genotype and allele frequency of rs2817035 and rs9470079 in CAD+H groups compared with the control subjects in all groups and the female groups $(P<0.05)$. Conclusions: The current study found a remarkable association between FKBP5 gene variations and the risk of comorbid CAD and depression in a north Chinese population. Rs9470079 may be a potential gene locus for the incidence of comorbid CAD and depression. 
$1 \quad$ Association of FKBP5 polymorphisms with patient susceptibility to

2

3

4

6 Jiangsu, 222000, China.

7 2, Department of Pharmacy, Hainan General Hospital,Haikou 570311,China

8 3, Department of Pharmacy, Affiliated Jining First People's Hospital of Jining Medical

9 University, Jining Medical University; No. 6, Jiankang Road, Jining, Shandong 272000, China

10

11

12

13

14

15

16

17

18

19

20

21

22

23

24

25

26

${ }^{*}$ Corresponding Author:

Pei Jiang

Affiliated Jining First People's Hospital of Jining Medical University, Jining Medical University, No. 6, Jiankang Road, Jining, Shandong 272000, China

e-mail:jiangpeicsu@sina.com

Tel: +865372106208 Fax: +86 5372106208

+ These authors contributed equally to this work. 
28 Background: Coronary artery disease (CAD) and depression cause great burden to society and

frequently co-occur. The exact mechanisms of this comorbidity are unclear. FK506-binding protein 51 (FKBP51) is correlated with cardiovascular disease and depression. The aim of this study was to determine the role of the seven single nucleotide polymorphisms (SNPs) of FKBP5 that code FKBP51, namely, rs1360780 (C>T), rs2817032 (T>C), rs2817035 (G>A), rs9296158 $(\mathrm{G}>A)$, rs9470079 (G>A), rs4713902 $(\mathrm{T}>\mathrm{C})$, and rs3800373 $(\mathrm{C}>\mathrm{T})$ in a patient's susceptibility to comorbid CAD and depression.

Methods: We enrolled 271 Northern Chinese Han patients with CAD, including 123 patients with depression and 147 patients without depression. We also included 113 healthy controls that match the patients' sex and age. Genomic DNA from whole blood was extracted, and seven SNPs were assessed using MassArray method. Patient Health Questionnaire-9 was applied to access the depression.

Results: The GA genotype for rs9470079 was associated with a significantly decreased risk of $\mathrm{CAD}$ (odds ratio $=0.506,95 \%$ confidence interval $=0.316-0.810, \mathrm{P}=0.005$ ) when the $\mathrm{GG}$ genotype was used as reference. A statistically significant difference was observed among females but not among males in the rs9470079 genotype and allele frequency. Patients with $\mathrm{CAD}$ were further divided into $\mathrm{CAD}+\mathrm{D}$ and $\mathrm{CAD}-\mathrm{D}$ groups according to the presence of comorbid depression and were compared with the controls. Significant differences were found regarding the genotype and allele frequency of rs2817035 and rs9470079 in CAD+H groups compared with the control subjects in all groups and the female groups $(\mathrm{P}<0.05)$. 
48 Conclusions: The current study found a remarkable association between FKBP5 gene variations

49 and the risk of comorbid CAD and depression in a north Chinese population. Rs9470079 may be

50 a potential gene locus for the incidence of comorbid CAD and depression.

51 KEYWORDS: coronary artery diseases, depression, FKBP5, polymorphisms

52

53

54

55

56

57

58

59

60

61

62

63

64

65

66

67

68

Peer) reviewing PDF | (2020:01:44940:1:3:NEW 30 Apr 2020) 


\section{Introduction}

70 Coronary artery disease (CAD) is a major public health challenge globally; CAD is responsible

71 for approximately $32 \%$ of deaths worldwide, which exceeds that of all cancers combined in most

72 developed countries (2017; Benjamin et al., 2017) Depression is a psychological complication that may occur alongside CAD; it is an under-recognized determinant of outcomes in patients with CAD because of its high sudden death rate and poor prognostic association with CAD (Huffman et al., 2013; Raison et al., 2006). Major depressive disorder and minor depression affect $20 \%$ and $30 \%-45 \%$ of patients with CAD, respectively (Baghai et al., 2018).

The direction and cause mechanism of the association between CAD and depression remain unclear. However, many studies have demonstrated their shared risk factors, including hypercortisolemia, inflammation, autonomic arousal, serotonin signaling-altered platelet function, and hypothalamus-pituitary-adrenocortical (HPA) axis dysfunction (Lett et al., 2004). Genetic factors contribute to the comorbidity of CAD and depression. Genome-wide association study (GWAS), a non-hypothesis-driven and unbiased approach, is a standard tool used to analyze the potential associations between the traits of a disease and single nucleotide polymorphisms (SNPs). Numerous GWASs have been implemented to investigate CAD and depression and involved tens of thousands of case and controls from a great range of geographic, demographic, and ethnic backgrounds. (Guo et al., 2017; Nurnberg et al., 2016; Ormel et al., 2016) Over 60

87 CAD loci were identified for CAD susceptibility. (Nikpay., et al., 2015) According to a GWAS of depression in 2018, 17 variants in excitatory synaptic pathways were identified by a UK

Biobank study. (Howard ., et al., 2018) However, no GWAS of comorbid CAD and depression 
90

91

92

93

94

95

96

97

has been reported. By contrast to GWAS, candidate gene study, which is an approach based on hypothesis, has been applied to uncover the genetic basis of susceptibility to diseases. For example, some gene studies have revealed the association of comorbid CAD and depression with genetic defects in plasminogen activator inhibitor 1, 5-hydroxytryptamine, and apolipoprotein E (Fritze et al., 2011; Golimbet et al., 2012; Lahlou-Laforet et al., 2006).

FK506-binding protein (FKBP) is coded by the FKBP gene, which is located on chromosome 6. FKBP51 is an important member of the FKBP protein family and is coded by FKBP5. FKBP5 is a vital modulator that regulates the amount of biological processes in the periphery and the brain and is a regulator of glucocorticoid receptors (GRs), which are associated with the HPA axis function (Appelhof et al., 2006). Glucocorticoids can increase FKBP5 gene expression in various tissues in a dose-dependent manner (Lee et al., 2018). GR condition and HPA axis function are closely related to the pathogenesis of CAD and depression (Dickens, 2015). Systematic reviews and meta-analysis studies have proven that the SNPs of FKBP5 are associated with depression (Normann and Buttenschon, 2019; Piechaczek et al., 2019). FKBP5 expression is associated with insulin resistance, type 2 diabetes, and obesity, which are closely related to cardiovascular disease (Fichna et al., 2018; Sidibeh et al., 2018). The regulation of FKBP5 may be associated with cardiometabolic risk (Ortiz et al., 2018; Zannas et al., 2019). Thus, we can reasonably assume that FKBP5 is associated with CAD susceptibility.

Given its associations with CAD and depression, we speculated that the FKBP5 gene may be the gene underlying the comorbidity of CAD and depression. This study aimed to investigate the association of FKBP5 polymorphisms with the susceptibility to comorbid depression in patients 
111 with CAD from a Northern Chinese population. Seven SNPs, namely, rs1360780 (C>T),

112 rs2817032 (T>C), rs2817035 (G>A), rs9296158 (G>A), rs9470079 (G>A), rs4713902 (T>C),

113 and rs3800373 (C>T), were selected. Their correlation with the comorbidity was evaluated.

\section{2. Methods}

\section{2.1. Subjects}

116 This study recruited participants from the First Peoples' Hospital of Jining between February

1172016 and May 2018. A total of 270 northern Han Chinese patients with CAD and 113 healthy

118 controls matched with patients' sex and age were enrolled in this study. All patients with CAD

119 were diagnosed by experienced cardiologists on the basis of significant standards: angiographic

120 evidence of luminal diameter narrowing $>50 \%$ in at least one main coronary artery, previous

121 history of coronary artery bypass graft surgery, and history of percutaneous coronary

122 intervention. Patients with renal failure, congenital heart disease, tumors, immune system

123 disorders, malignancies, congenital heart disease, and infectious heart disease were excluded.

124 CAD patients with or without depression were assessed by at least two experienced psychiatrists

125 on the basis of the fifth edition of the Diagnostic and Statistical Manual of Mental Disorders for

126 depressive disorder, characterized by significant anhedonia and depressed mood. Patient Health

127 Questionnaire-9 (PHQ-9), a commonly used 9-item questionnaire, was used to assess the severity

128 of depressive symptoms. A score that was equal or greater than 5 was used as the cutoff score for

129 depression.(Duko et al., 2018)

130 Health controls were selected from the physical examination program through clinical

131 examination and electrocardiogram at the same period. This study was designed in accordance 
132

133

134

135

136

137

138

139

140

141

142

143

144

145

146

147

148

149

150

151

152

with the Declaration of Helsinki and approved by the ethics committee of the First Peoples' Hospital of Jining (approval number: JY2016035). All subjects provided written informed consent.

2.2. DNA Isolation and Genotyping. About $1 \mathrm{ml}$ of peripheral blood was collected and extracted from the subjects using a TIANamp Blood DNA Kit (TIANGEN, China) according to the manufacturer's instructions. The concentration and purity of DNA samples were detected with NanoDrop-1000 (NanoDrop, USA) to ensure that the samples were available for subsequent experiments. All DNA samples were genotyped through polymerase chain reaction (PCR)-ligase detection reaction. PCR of the four target single-nucleotide polymorphisms was amplified by the primers listed in Table 1 from each participant. The samples were processed by shrimp alkaline phosphatase, extended, and purified using iPLEX extension reagents (Agena Bioscience, USA) and Nanodispenser RS1000. Matrix-assisted laser desorption/ionization time-of-flight mass spectrometry was conducted to detect the primer extension products, and Spectro-Typer was used to automatically analyze the genotyping data. More than $10 \%$ of the samples were randomly selected and retested to verify the validity of MassARRAY results.

2.3. Statistical Analysis. All genotyping results of the investigated patients and controls were tested for Hardy-Weinberg equilibrium (HWE) by applying the chi-square test ( $\chi^{2}$ test). Differences in genotypic distributions and allele frequencies in the cases and controls were compared among groups for statistical significance through chi-square statistics $(\chi 2$ test). The associations between the genotypes and $\mathrm{CAD} / \mathrm{CAD}$ with comorbid depression were evaluated via the odds ratio (OR), with $95 \%$ confidence interval $(\mathrm{CI})$. A two-sided p value below 0.05 was 
153

154 Windows (SPSS Inc., Chicago, IL, USA).

considered statistically significant. All statistical analyses were performed with SPSS 17.0 for

\section{3. Results}

156

Table 2 shows the demographic and clinical characteristics of the participants in this study., No

157 significant differences were found between the CAD and the health control groups in term of age, gender, smoking, drinking and body mass index (BMI) $(\mathrm{P}>0.05)$. No significant differences were observed when the CAD cases were subdivided to the CAD with depression $(C A D+D)$ and CAD without depression (CAD-D) groups based on comorbid depression.

The results demonstrated that the seven observed genotype frequencies were in accordance with the HWE ( $\mathrm{P} \geq 0.088)$. The genotypic distribution and allele frequencies of the seven genetic polymorphisms between the CAD and control groups in all participants, male participants only, and female participants only were compared (Table 3 for all participants, Table 4 for female participants with significant results and Supplementary Table for all male participants and all female participants). No statistically significant difference was observed between the patients with CAD and controls for the genotypic and allelic distributions of the rs1360780 (C>T),

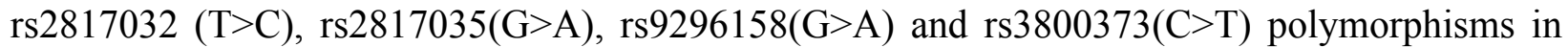
the investigated group, including all, male or female participants. The TC+CC genotype frequency for rs4713902 was significantly higher in the CAD cases than

171 in the controls $(\mathrm{P}=0.049)$. For rs9470079, the GA and GA+AA genotypes were associated with significantly decreased risks of CAD $(\mathrm{OR}=0.506,95 \% \mathrm{CI}=0.316-0.810, \mathrm{p}=0.005$ and $\mathrm{OR}=$ $0.502,95 \% \mathrm{CI}=0.320-0.788, \mathrm{p}=0.003$ for $\mathrm{GA}$ and $\mathrm{GA}+\mathrm{AA}$, respectively) when the GG 
174 genotype was used as the reference The A allele showed a significant association with the CAD

175 group $(\mathrm{OR}=0.626,95 \% \mathrm{CI}=0.450-0.871, \mathrm{p}=0.005)$.

176 Interestingly, no statistically significant difference was found in males in terms of the rs9470079

177 genotype and allele frequency, whereas a statistically significant difference was observed among

178 females $(\mathrm{OR}=0.419,95 \% \mathrm{CI}=0.220-0.799, \mathrm{p}=0.008$ for $\mathrm{GA}$ vs. $\mathrm{GG}$; $\mathrm{OR}=0.406,95 \% \mathrm{CI}=$

$1790.219-0.752, \mathrm{p}=0.004$ for $\mathrm{GA}+\mathrm{AA}$ vs. $\mathrm{GG} ; \mathrm{OR}=0.545,95 \% \mathrm{CI}=0.344-0.862, \mathrm{p}=0.010$ for $\mathrm{A}$ 180 vs. G).

181 The patients with CAD were divided into the CAD+D and CAD-D groups based on comorbid 182 depression, and all the investigated genotype and allele frequency distributions of polymorphisms were compared within the CAD+D, CAD-D, and healthy groups. The genotype frequencies of the subgroups were compared with those of the controls, and the results are

presented in Table 5, No significant associations were observed in rs1360780 (C>T), rs2817032

$(\mathrm{T}>\mathrm{C}), \mathrm{rs} 2817035(\mathrm{G}>\mathrm{A})$ and $\mathrm{rs} 3800373(\mathrm{C}>\mathrm{T})$ SNPs and CAD of the subgroups $(\mathrm{P}>0.05)$. A significant difference in the genotype and allele frequencies of rs2817035 and rs9470079 was noted in the $\mathrm{CAD}+\mathrm{H}$ groups compared with the control subjects $(\mathrm{P}<0.05$ for both comparisons).

A significant difference was found in the allele frequency of the rs4713902 polymorphism in the

$190 \mathrm{CAD}+\mathrm{H}$ groups compared with the control subjects $(\mathrm{P}=0.034)$.

191

Stratification comparison by gender was performed for genotype and allele frequencies of rs9470079 in the CAD+D, CAD-D and healthy groups. The results present in Table 6. The combination of the rs9470079 polymorphism was not associated with CAD comorbid depression or not in male group. However, significant differences were observed in the genotype frequency 
195 of rs9470079 in both $\mathrm{CAD}+\mathrm{D}$ and CAD-D groups compared with the female control group $(\mathrm{P}=$

1960.039 and $\mathrm{P}=0.036$, respectively). Allele frequency of the rs9470079 polymorphism was

197 significantly different in the $\mathrm{CAD}+\mathrm{D}$ and CAD-D groups compared with the female control 198 group $(\mathrm{P}=0.019$ and $\mathrm{P}=0.013$, respectively $)$.

199

200

\section{Discussion}

201

FKBP51 is a FK506-binding protein with high molecular weight and is coded by the FKBP5

gene, which consists of 13 exons located on chromosome 6 (6p21.31). FKBP51 has important

roles in the pathogenesis of psychological complications, such as depression, obsessive-

compulsive disorder, and schizophrenia (Daskalakis and Binder, 2015; Ferrer et al., 2018).

FKBP51 affects GR activity by reducing its binding affinity and regulating the HPA axis.

FKBP51 can inhibit other steroid hormone receptors, including progesterone and androgen

receptors (Jaaskelainen et al., 2011). The conditions of GRs, HPA axis, and steroid hormone

receptors are related to the pathogenesis of CAD. Some studies reported an association between the FKBP5 gene and cardiovascular risk.

210 GWAS is a powerful way to identify the genes involved in human disease, but this approach has

211 not detected the effects of the FKBP5 locus. (Hähle et al., 2019) However, FKBP5 gene

212 variations have been associated with risks for varying disorders. Thus, we investigated the

association of FKBP5 gene polymorphisms with the susceptibility of patients with CAD in a northern Chinese population. The GA and GA+AA genotypes of rs9470079 were associated with

215 a remarkably decreased risk of CAD. The exact mechanism underlying the effect of FKBP5 on 
216 CAD is unclear, but some reports have provided evidence of the processes involved. The

217 epigenetic upregulation of FKBP5 caused by aging and stress is driven by FKBP5-nuclear factor

218 kappa-light-chain-enhancer of activated B cell signaling, mediates inflammation, and contributes

219 to cardiovascular risk (Zannas et al., 2019). Ortiz et al., (2018) stated that cardiometabolic risk

220 may be associated with increased DNA methylation of FKBP5, which is associated with the risk

221 factors for CAD, such as the higher levels of glycosylated hemoglobin, low-density lipoprotein

222 cholesterol, body mass index, and waist circumference. Moreover, FKBP5 increases platelet

223 expression in patients with myocardial infarction, which mostly occurs because of CAD (Eicher

224 et al., 2016).

225 We further classified the CAD group into $\mathrm{CAD}+\mathrm{D}$ and $\mathrm{CAD}-\mathrm{D}$ groups depending on the

226 presence of comorbid depression to investigate the association of FKBP5 gene polymorphism

227 with susceptibility to CAD with comorbid depression. The genotypes and alleles of rs 2817035

228 and rs9470079 and the alleles of rs4713902 showed significant differences only between the

$229 \mathrm{CAD}+\mathrm{D}$ and control groups but not between the CAD-D and control groups and between

$230 \mathrm{CAD}+\mathrm{D}$ and CAD-D groups. Rs4713902 polymorphisms interact with chronic low family

231 support in association with a child's mental health status (Adrian et al., 2015). Ferrer et al. (2018)

232 reported that individuals with rs9470079-A show a reduced dexamethasone suppression test ratio

233 and suggested a probable effect between the FKBP5 rs9470079 polymorphism and impaired

234 HPA axis negative feedback in major depression. However, we did not find any remarkable

235 differences in these FKBP5 polymorphisms for the CAD+D group compared with the CAD-D

236 and healthy control groups. Other studies focused on the effect of FKBP5 SNPs rs1360780 and 
237

238

239

240

241

242

243

244

245

246

247

248

249

250

251

252

253

254

255

256

257

rs3800373 on depression. Normann and Buttenschon (2019) revealed that rs1360780 possibly

moderates the effects of systemic lupus erythematous in depression and that rs3800373 is

associated with a remarkable increased risk of depressive disorders. We failed to demonstrate the

association between the $\mathrm{CAD}+\mathrm{D}$ and $\mathrm{CAD}-\mathrm{D}$ group or healthy control groups for rs 1360780 or

rs3800373. These results suggested that common depression and depression comorbid with CAD

may have different pathogenetic mechanisms.

CAD is a sex-dependent disease that is two to five times more common in middle-aged men than in their women counterparts; its incidence has decreased in men but has increased in women (Shively et al., 2009; Yang et al., 2010). Our results presented a remarkable association between rs9470079 and CAD in the female groups but not in the male groups. Depressive disorders are twice as likely to occur in women than in men (Gorman, 2006). Thus, we investigated the genotypic and allelic distributions of the rs9470079 polymorphism in the CAD+D, CAD-D, and control groups between different genders. The results showed a significant difference in the genotypic and allelic distributions of the rs9470079 polymorphisms in the CAD+D and CAD-D groups compared with the controls in the female groups but not in the male groups. Thus, genetics may play different roles in different genders. The present results were consistent with those of a previous study on depression and CAD in Swedish twins (Kendler et al., 2009), which demonstrated that genetic sources play a large role in $\mathrm{CAD}+\mathrm{D}$ comorbidity in women, whereas environmental effects play a large role in CAD-D in men. The FKBP5 gene contains hormone response elements that can bind receptors to sex hormones (Magee et al., 2006). These elements have different levels in males and females and may play a role in the association of CAD with 
258

259

260

261

262

263

264

265

266

267

268

269

270

271

272

273

274

275

276

277

278

comorbid depression in different genders.

Several limitations of this study had to be mentioned. First, this study only evaluated a small population in northern China, and the sample size was limited. Genetic polymorphisms of ethnic differences may determine varying functions in different populations. Thus, large sample sizes from different groups are required to obtain reliable outcomes. Second, this study only tested seven of the genotypes of FKBP5 and the tagging of the FKBP5 gene was incomplete. Thus, this study could not fully reflect the association of the polymorphisms of FKBP5 with comorbid CAD and depression. A previous study spanning the whole FKBP5 gene showed 18 SNPs in strong linkage disequilibrium among Caucasians. (Zannas et al., 2016) However, we did not found linkage disequilibrium in our study (data no shown), probably owing to the limited number of samples or the incomplete gene locus. Third, the data on FKPB51 level were insufficient, and we failed to assess the influence of FKBP5 expression on the incidence of comorbid CAD and depression by regulating the FKPB51 level.

\section{Conclusion}

The current study proposed a remarkable association between FKBP5 gene variations and the risk of comorbid CAD and depression in a Northern Chinese population. Rs9470079 may be a potential gene locus for the incidence of comorbid CAD and depression. The present findings should be verified through replication studies on large ethnically disparate specimens and with variants covering the whole gene. The exact role of FKBP5 gene polymorphisms in the pathogenesis of comorbid CAD and depression requires further investigation.

\section{Reference}


2017. Global, regional, and national age-sex specific mortality for 264 causes of death, 19802016: a systematic analysis for the Global Burden of Disease Study 2016. Lancet (London, England) 390, 1151-1210.

Adrian, M., Kiff, C., Glazner, C., Kohen, R., Tracy, J.H., Zhou, C., McCauley, E., Vander Stoep, A., 2015. Examining gene-environment interactions in comorbid depressive and disruptive behavior disorders using a Bayesian approach. Journal of psychiatric research 68, 125-133.

Appelhof, B.C., Huyser, J., Verweij, M., Brouwer, J.P., van Dyck, R., Fliers, E., Hoogendijk, W.J., Tijssen, J.G., Wiersinga, W.M., Schene, A.H., 2006. Glucocorticoids and relapse of major depression (dexamethasone/corticotropin-releasing hormone test in relation to relapse of major depression). Biological psychiatry 59, 696-701.

Baghai, T.C., Varallo-Bedarida, G., Born, C., Hafner, S., Schule, C., Eser, D., Zill, P., Manook, A., Weigl, J., Jooyandeh, S., Nothdurfter, C., von Schacky, C., 2018. Classical Risk Factors and Inflammatory Biomarkers: One of the Missing Biological Links between Cardiovascular Disease and Major Depressive Disorder. 19.

Benjamin, E.J., Blaha, M.J., Chiuve, S.E., Cushman, M., Das, S.R., Deo, R., de Ferranti, S.D., Floyd, J., Fornage, M., Gillespie, C., Isasi, C.R., Jimenez, M.C., Jordan, L.C., Judd, S.E., Lackland, D., Lichtman, J.H., Lisabeth, L., Liu, S., Longenecker, C.T., Mackey, R.H., Matsushita, K., Mozaffarian, D., Mussolino, M.E., Nasir, K., Neumar, R.W., Palaniappan, L., Pandey, D.K., Thiagarajan, R.R., Reeves, M.J., Ritchey, M., Rodriguez, C.J., Roth, G.A., Rosamond, W.D., Sasson, C., Towfighi, A., Tsao, C.W., Turner, M.B., Virani, S.S., Voeks, J.H., Willey, J.Z., Wilkins, J.T., Wu, J.H., Alger, H.M., Wong, S.S., Muntner, P., 2017. Heart Disease and Stroke Statistics-2017 Update: A Report From the American Heart Association. Circulation 135, e146-e603.

Daskalakis, N.P., Binder, E.B., 2015. Schizophrenia in the spectrum of gene-stress interactions: the FKBP5 example. Schizophrenia bulletin 41, 323-329.

Dickens, C., 2015. Depression in people with coronary heart disease: prognostic significance and mechanisms. Current cardiology reports 17, 83.

Duko, B., Geja, E., Zewude, M., Mekonen, S., 2018. Prevalence and associated factors of depression among patients with HIV/AIDS in Hawassa, Ethiopia, cross-sectional study. Annals of general psychiatry 17, 45.

Eicher, J.D., Wakabayashi, Y., Vitseva, O., Esa, N., Yang, Y., Zhu, J., Freedman, J.E., McManus, D.D., Johnson, A.D., 2016. Characterization of the platelet transcriptome by RNA sequencing in patients with acute myocardial infarction. Platelets 27, 230-239.

Ferrer, A., Costas, J., Labad, J., Salvat-Pujol, N., Segalas, C., Urretavizcaya, M., Real, E., de Arriba-Arnau, A., Alonso, P., Crespo, J.M., Barrachina, M., Soriano-Mas, C., Carracedo, A., Menchon, J.M., Soria, V., 2018. FKBP5 polymorphisms and hypothalamic-pituitary-adrenal axis negative feedback in major depression and obsessive-compulsive disorder. Journal of psychiatric research 104, 227-234.

Fichna, M., Krzysko-Pieczka, I., Zurawek, M., Skowronska, B., Januszkiewicz-Lewandowska, D., Fichna, P., 2018. FKBP5 polymorphism is associated with insulin resistance in children and adolescents with obesity. Obesity research \& clinical practice 12, 62-70. 
320

321

322

323

324

325

326

327

328

329

330

331

332

333

334

335

336

337

338

339

340

341

342

343

344

345

346

347

348

349

350

351

352

353

354

355

356

357

358

359

360

Fritze, F., Ehrt, U., Sonnesyn, H., Kurz, M., Hortobagyi, T., Nore, S.P., Ballard, C., Aarsland, D., 2011. Depression in mild dementia: associations with diagnosis, APOE genotype and clinical features. International journal of geriatric psychiatry 26, 1054-1061.

Golimbet, V.E., Volel, B.A., Dolzhikov, A.V., Isaeva, M.I., 2012. [The role of the 5-HTTLPR polymorphism of the serotonin transporter gene in the development of depression in patients with coronary heart disease]. Zhurnal nevrologii i psikhiatrii imeni S.S. Korsakova 112, 6369.

Gorman, J.M., 2006. Gender differences in depression and response to psychotropic medication. Gender medicine 3, 93-109.

Guo, Y., Wang, F., Li, L., Gao, H., Arckacki, S., Wang, I. Z., ... \& Wang, Q. K., 2017. GenomeWide Linkage Analysis of Large Multiple Multigenerational Families Identifies Novel Genetic Loci for Coronary Artery Disease. Scientific Reports, 7.

Hähle, A, Merz, S, Meyners, C, Hausch, F. 2019, The Many Faces of FKBP51. Biomolecules. 9, pii: E35.

Howard, D.M., Adams, M.J., Shirali, M., Clarke, T., Marioni, R.E., Davies, G., Mcintosh, A.M., 2018. Addendum: Genome-wide association study of depression phenotypes in UK Biobank identifies variants in excitatory synaptic pathways. Nature Communications, 9, 1470-1470.

Huffman, J.C., Celano, C.M., Beach, S.R., Motiwala, S.R., Januzzi, J.L., 2013. Depression and cardiac disease: epidemiology, mechanisms, and diagnosis. Cardiovascular psychiatry and neurology 2013, 695925.

Jaaskelainen, T., Makkonen, H., Palvimo, J.J., 2011. Steroid up-regulation of FKBP51 and its role in hormone signaling. Current opinion in pharmacology 11, 326-331.

Kendler, K.S., Gardner, C.O., Fiske, A., Gatz, M., 2009. Major depression and coronary artery disease in the Swedish twin registry: phenotypic, genetic, and environmental sources of comorbidity. Archives of general psychiatry 66, 857-863.

Lahlou-Laforet, K., Alhenc-Gelas, M., Pornin, M., Bydlowski, S., Seigneur, E., Benetos, A., Kierzin, J.M., Scarabin, P.Y., Ducimetiere, P., Aiach, M., Guize, L., Consoli, S.M., 2006. Relation of depressive mood to plasminogen activator inhibitor, tissue plasminogen activator, and fibrinogen levels in patients with versus without coronary heart disease. The American journal of cardiology 97, 1287-1291.

Lee, R.S., Mahon, P.B., Zandi, P.P., McCaul, M.E., Yang, X., Bali, U., Wand, G.S., 2018. DNA methylation and sex-specific expression of FKBP5 as correlates of one-month bedtime cortisol levels in healthy individuals. Psychoneuroendocrinology 97, 164-173.

Lett, H.S., Blumenthal, J.A., Babyak, M.A., Sherwood, A., Strauman, T., Robins, C., Newman, M.F., 2004. Depression as a risk factor for coronary artery disease: evidence, mechanisms, and treatment. Psychosomatic medicine 66, 305-315.

Magee, J.A., Chang, L.W., Stormo, G.D., Milbrandt, J., 2006. Direct, androgen receptormediated regulation of the FKBP5 gene via a distal enhancer element. Endocrinology 147, 590-598.

Nikpay, M., Goel, A., Hh, W., Hall, L. M., Willenborg, C., Kanoni, S., Farrall, M., 2015. A comprehensive 1000 Genomes-based genome-wide association meta-analysis of coronary 
artery disease. Nature Genetics, 47, 1121-1130.

Normann, C., Buttenschon, H.N., 2019. Gene-environment interactions between HPA-axis genes and stressful life events in depression: a systematic review. Acta neuropsychiatrica 31, 186192.

Nurnberg, S.T., Zhang, H., Hand, N.J., Bauer, R.C., Saleheen, D., Reilly, M.P., Rader, D.J., 2016. From Loci to Biology: Functional Genomics of Genome-Wide Association for Coronary Disease. Circulation Research, 118, 586-606.

Ormel, J., Hartman, C. A., Snieder, H., 2019. The genetics of depression: successful genomewide association studies introduce new challenges. Translational Psychiatry, 9.

Ortiz, R., Joseph, J.J., Lee, R., Wand, G.S., Golden, S.H., 2018. Type 2 diabetes and cardiometabolic risk may be associated with increase in DNA methylation of FKBP5. Clinical epigenetics 10, 82.

Piechaczek, C.E., Greimel, E., Feldmann, L., Pehl, V., Allgaier, A.K., Frey, M., Freisleder, F.J., Halldorsdottir, T., Binder, E.B., Ising, M., Schulte-Korne, G., 2019. Interactions between FKBP5 variation and environmental stressors in adolescent Major Depression. Psychoneuroendocrinology 106, 28-37.

Raison, C.L., Capuron, L., Miller, A.H., 2006. Cytokines sing the blues: inflammation and the pathogenesis of depression. Trends in immunology 27, 24-31.

Shively, C.A., Musselman, D.L., Willard, S.L., 2009. Stress, depression, and coronary artery disease: modeling comorbidity in female primates. Neuroscience and biobehavioral reviews 33, 133-144.

Sidibeh, C.O., Pereira, M.J., Abalo, X.M., G, J.B., Skrtic, S., Lundkvist, P., Katsogiannos, P., Hausch, F., Castillejo-Lopez, C., Eriksson, J.W., 2018. FKBP5 expression in human adipose tissue: potential role in glucose and lipid metabolism, adipogenesis and type 2 diabetes. Endocrine 62, 116-128.

Yang, C., Wang, X., Geng, C., Ding, H., 2010. Prevention of coronary artery disease in men: male hormone, female hormone, or both? Medical hypotheses 75, 671-673.

Zannas, A.S., Jia, M., Hafner, K., Baumert, J., Wiechmann, T., Pape, J.C., Arloth, J., Kodel, M., Martinelli, S., Roitman, M., Roh, S., 2019. Epigenetic upregulation of FKBP5 by aging and stress contributes to NF-kappaB-driven inflammation and cardiovascular risk 116, 1137011379.

Zannas, A.S., Wiechmann, T., Gassen, N.C., \& Binder, E.B., 2016. Gene-Stress-Epigenetic Regulation of FKBP5 : Clinical and Translational Implications. Neuropsychopharmacology 41, 261-274. 
Table $\mathbf{1}$ (on next page)

Table1 Primers of FKBP5 Genes Used in the PCR 
1

\begin{tabular}{|c|c|c|c|}
\hline SNP & $\begin{array}{l}\text { Ancestor } \\
\text { allele }\end{array}$ & Primer sequence & $\begin{array}{l}\text { Product } \\
\text { size }\end{array}$ \\
\hline rs1360780 & $\mathrm{C}$ & $\begin{array}{l}\text { 5'-ACGTTGGATGTGCCAGCAGTAGCAAGTAAG-3' } \\
\text { 5'-ACGTTGGATGCAGGCACAGAAGGCTTTCAC-3' }\end{array}$ & 88 \\
\hline rs2817032 & $\mathrm{T}$ & $\begin{array}{l}\text { 5'- ACGTTGGATGTTTCACAGGTACCCCATTCC-3' } \\
\text { 5'-ACGTTGGATGAATATCACAGGCTTGCTGGG-3' }\end{array}$ & 103 \\
\hline rs2817035 & G & $\begin{array}{l}\text { 5'-ACGTTGGATGGTTGCAAACAGAGGTAGGAG-3' } \\
\text { 5'- ACGTTGGATGCTCTTTTCTCCTAGGATCCC-3' }\end{array}$ & 99 \\
\hline rs9296158 & G & $\begin{array}{l}\text { 5'- ACGTTGGATGGACCTGGTAATATCACTCTC-3' } \\
\text { 5'- ACGTTGGATGCTGGGCTAGGGGTAATTCAA-3' }\end{array}$ & 118 \\
\hline rs9470079 & G & $\begin{array}{l}\text { 5'- ACGTTGGATGGCCTCCCAAAATGCTATATC-3' } \\
\text { 5'-ACGTTGGATGATACCATACTCTAGGCTGGG-3' }\end{array}$ & 104 \\
\hline rs4713902 & $\mathrm{T}$ & $\begin{array}{l}\text { 5'-ACGTTGGATGGGAGCCAAAACATGAAGAGC-3' } \\
\text { 5'-ACGTTGGATGTAGGCAACCTGTATAAGCTG-3' }\end{array}$ & 99 \\
\hline rs3800373 & $\mathrm{C}$ & $\begin{array}{l}\text { 5'-ACGTTGGATGTGACTTTTTAGTACTAAGC-3' } \\
\text { 5'-ACGTTGGATGCCCTAGTGTAGAAGAGCAAC-3' }\end{array}$ & 101 \\
\hline
\end{tabular}

Table1 Primers of FKBP5 Genes Used in the PCR 


\section{Table 2 (on next page)}

Table 2 Demographic and Clinical Characteristics of the Participants

${ }^{a} C A D$ versus Controls, ${ }^{b} C A D+D$ versus Controls, ${ }^{C} C A D+D$ versus CAD-D. CAD: coronary heart disease, $C A D+D$ : CHD with depression, CAD-D: CAD without depression 
Table 2 Demographic and Clinical Characteristics of the Participants

\begin{tabular}{|c|c|c|c|c|c|c|c|}
\hline Variables & $\begin{array}{l}\text { CAD } \\
(n=270)\end{array}$ & $\begin{array}{l}\text { Controls } \\
(n=113)\end{array}$ & P-value ${ }^{a}$ & $\begin{array}{l}C A D+D \\
(n=123)\end{array}$ & P-value ${ }^{b}$ & $\begin{array}{l}\text { CAD-D } \\
(n=147)\end{array}$ & P-value ${ }^{c}$ \\
\hline Age (yrs) & $56.2 \pm 10.4$ & $52.9 \pm 10.2$ & 0.887 & $57.1 \pm 10.2$ & 0.977 & $55.5 \pm 10.5$ & 0.820 \\
\hline Gender $(\mathrm{M} / \mathrm{F}, \mathrm{n})$ & $128 / 142$ & $52 / 61$ & 0.804 & $53 / 70$ & 0.651 & $75 / 72$ & 0.424 \\
\hline Smoking (n, \%) & $88,32.5$ & $28,24.8$ & 0.129 & $36,29.3$ & 0.438 & $52,35.3$ & 0.067 \\
\hline Drinking (n, \%) & $93,34.4$ & $33,29.2$ & 0.319 & $35,28.4$ & 0.899 & $58,39.4$ & 0.086 \\
\hline BMI $\left(\mathrm{kg} / \mathrm{m}^{2}\right)$ & $24.3 \pm 3.3$ & $24.0 \pm 3.0$ & 0.205 & $24.4 \pm 3.6$ & 0.119 & $24.2 \pm 2.9$ & 0.983 \\
\hline
\end{tabular}

2

$3 \quad{ }^{a} \mathrm{CAD}$ versus Controls, ${ }^{\mathrm{b}} \mathrm{CAD}+\mathrm{D}$ versus Controls, ${ }^{\mathrm{c}} \mathrm{CAD}+\mathrm{D}$ versus $\mathrm{CAD}-\mathrm{D}$.

4 CAD: coronary heart disease, $\mathrm{CAD}+\mathrm{D}$ : $\mathrm{CHD}$ with depression, CAD-D: $\mathrm{CAD}$ without depression 


\section{Table 3 (on next page)}

Table 3 Genotypic and Allelic Distribution of seven FKBP5 Gene Between All CAD Patients $(n=270)$ and Controls $(n=113)$.

Abbreviations: $\mathrm{Cl}$, confidence interval; OR, odds ratio. ${ }^{\text {a }}$ vvalue for genotype and allele frequencies in cases and controls using 2 -sided $\chi^{2}$ test. ${ }^{b} P$ values adjusted by age and gender using logistic regression. $* P<0.05$ 
1 Table 3 Genotypic and Allelic Distribution of seven FKBP5 Gene Between All CAD Patients $2 \quad(\mathrm{n}=270)$ and Controls $(\mathrm{n}=113)$.

\begin{tabular}{|c|c|c|c|c|c|c|}
\hline SNP & $\begin{array}{l}\text { Genotype/ } \\
\text { allele }\end{array}$ & Case, $(\%)$ & Control, $(\%)$ & $P$ value $^{\mathrm{a}}\left(\chi^{2}\right)$ & OR $(95 \% \mathrm{CI})$ & $P$ value ${ }^{\mathrm{b}}$ \\
\hline \multirow[t]{6}{*}{ rs 1360780} & $\mathrm{CC}$ & $134(49.6)$ & $60(53.1)$ & $0.644(0.879)$ & 1.00 & Referent \\
\hline & $\mathrm{CT}$ & $121(44.8)$ & $49(43.4)$ & & $1.106(0.705-1.735)$ & 0.622 \\
\hline & TT & $15(5.6)$ & $4(3.5)$ & & $1.679(0.535-5.272)$ & 0.375 \\
\hline & $\mathrm{CT}+\mathrm{TT}$ & $136(50.4)$ & $53(46.9)$ & $0.536(0.383)$ & $1.149(0.740-1.784)$ & 0.563 \\
\hline & $\mathrm{C}$ & $389(72.0)$ & $169(74.8)$ & $0.437(0.605)$ & 1.00 & Referent \\
\hline & $\mathrm{T}$ & $151(28.0)$ & $57(25.2)$ & & $1.151(0.808-1.640)$ & 0.151 \\
\hline \multirow[t]{6}{*}{ rs 2817032} & TT & $142(52.6)$ & $69(61.1)$ & $0.253(2.748)$ & 1.00 & Referent \\
\hline & $\mathrm{TC}$ & $108(40.0)$ & $39(34.5)$ & & $1.346(0.845-2.144)$ & 0.211 \\
\hline & $\mathrm{CC}$ & $20(7.4)$ & $5(4.4)$ & & $1.944(0.700-5.397)$ & 0.202 \\
\hline & $\mathrm{TC}+\mathrm{CC}$ & $128(47.4)$ & 44 (38.9) & $0.129(2.310)$ & $1.414(0.904-2.211)$ & 0.129 \\
\hline & $\mathrm{T}$ & $392(72.6)$ & $177(78.3)$ & $0.098(2.734)$ & 1.00 & Referent \\
\hline & $\mathrm{C}$ & $148(27.4)$ & $49(21.7)$ & & $1.364(0.943-1.972)$ & 0.099 \\
\hline \multirow[t]{6}{*}{ rs 2817035} & GG & $121(44.8)$ & $61(54.0)$ & $0.040(6.429)^{*}$ & 1.00 & Referent \\
\hline & GA & $138(51.1)$ & $52(46.0)$ & & $1.338(0.859-2.084)$ & 0.198 \\
\hline & AA & $11(4.1)$ & $0(0.0)$ & & -- & -- \\
\hline & $\mathrm{GA}+\mathrm{AA}$ & $149(55.2)$ & $52(46.0)$ & $0.101(2.685)$ & $1.445(0.930-2.245)$ & 0.102 \\
\hline & $\mathrm{G}$ & $380(70.4)$ & $174(77.0)$ & $0.062(3.489)$ & 1.00 & Referent \\
\hline & A & $160(29.6)$ & $52(23.0)$ & & $1.409(0.982-2.021)$ & 0.062 \\
\hline \multirow[t]{6}{*}{ rs9296158 } & GG & $112(41.5)$ & 47 (41.6) & $0.994(0.013)$ & 1.00 & Referent \\
\hline & GA & $121(44.8)$ & $51(45.1)$ & & $0.996(0.621-1.597)$ & 0.985 \\
\hline & AA & 37 (13.7) & $15(13.3)$ & & $1.035(0.519-2.064)$ & 0.922 \\
\hline & $\mathrm{GA}+\mathrm{AA}$ & $158(58.5)$ & $66(58.4)$ & $0.984(0.000)$ & $1.005(0.643-1.569)$ & 0.984 \\
\hline & G & $345(63.9)$ & $145(64.2)$ & $0.943(0.005)$ & 1.00 & Referent \\
\hline & A & $195(36.1)$ & $81(35.8)$ & & $1.012(0.732-1.398)$ & 0.943 \\
\hline \multirow[t]{6}{*}{ rs9470079 } & GG & $146(54.1)$ & $42(37.2)$ & $0.010(9.121)^{*}$ & 1.00 & Referent \\
\hline & GA & $102(37.8)$ & $58(51.3)$ & & $0.506(0.316-0.810)$ & $0.005^{*}$ \\
\hline & $\mathrm{AA}$ & $22(8.1)$ & $13(11.5)$ & & $0.487(0.226-1.048)$ & 0.066 \\
\hline & $\mathrm{GA}+\mathrm{AA}$ & $124(45.9)$ & $71(62.8)$ & $0.003(9.110)^{*}$ & $0.502(0.320-0.788)$ & $0.003 *$ \\
\hline & $\mathrm{G}$ & $394(73.0)$ & $142(62.8)$ & $0.005(7.783)^{*}$ & 1.00 & Referent \\
\hline & A & $146(27.0)$ & $84(37.2)$ & & $0.626(0.450-0.871)$ & $0.005^{*}$ \\
\hline \multirow[t]{6}{*}{ rs4713902 } & TT & $145(53.7)$ & $73(64.6)$ & $0.114(4.351)$ & 1.00 & Referent \\
\hline & $\mathrm{TC}$ & $109(40.4)$ & $33(29.2)$ & & $1.663(1.029-2.688)$ & 0.038 \\
\hline & $\mathrm{CC}$ & $16(5.9)$ & $7(6.2)$ & & $1.151(0.435-2.921)$ & 0.768 \\
\hline & $\mathrm{TC}+\mathrm{CC}$ & $125(46.3)$ & $40(35.4)$ & $0.049(3.858)^{*}$ & $1.573(0.999-2.477)$ & $0.050^{*}$ \\
\hline & $\mathrm{T}$ & 399 (73.9) & $179(79.2)$ & $0.119(2.430)$ & 1.00 & Referent \\
\hline & $\mathrm{C}$ & $141(26.1)$ & $47(20.8)$ & & $1.346(0.999-2.477)$ & 0.120 \\
\hline
\end{tabular}




\begin{tabular}{rlllccl} 
rs3800373 & CC & $72(26.7)$ & $36(31.9)$ & $0.422(1.724)$ & 1.00 & Referent \\
& CA & $182(67.4)$ & $73(64.6)$ & & $2.000(0.623-6.421)$ & 0.244 \\
AA & $16(5.9)$ & $4(3.5)$ & & $1.247(0.769-2.022)$ & 0.372 \\
CA+AA & $198(73.3)$ & $77(68.1)$ & $0.980(0.001)$ & $0.994(0.607-1.625)$ & 0.980 \\
C & $326(60.4)$ & $145(64.2)$ & $0.326(0.966)$ & 1.00 & Referent \\
A & $214(39.6)$ & $81(35.8)$ & & $1.175(0.852-1.621)$ & 0.326 \\
\hline
\end{tabular}

3

4 Abbreviations: CI, confidence interval; OR, odds ratio.

$5 \quad{ }^{a} P$ value for genotype and allele frequencies in cases and controls using 2 -sided $\chi^{2}$ test.

$6 \quad$ b $P$ values adjusted by age and gender using logistic regression.

$7 * P<0.05$ 


\section{Table 4 (on next page)}

Table 4 Genotypic and Allelic Distribution of FKBP5 (rs9470079) Gene Between Female CAD Patients $(n=142)$ and Controls $(n=61)$.

Abbreviations: $\mathrm{Cl}$, confidence interval; OR, odds ratio. ${ }^{\text {a }}$ vvalue for genotype and allele frequencies in cases and controls using 2 -sided $\chi^{2}$ test. ${ }^{b} P$ values adjusted by age and gender using logistic regression. $* P<0.05$ 
1

2 Table 4 Genotypic and Allelic Distribution of FKBP5 (rs9470079) Gene Between Female CAD

3 Patients $(\mathrm{n}=142)$ and Controls $(\mathrm{n}=61)$.

\begin{tabular}{ccllccl}
\hline \multirow{2}{*}{ SNP } & $\begin{array}{c}\text { Genotype/ } \\
\text { allele }\end{array}$ & \multicolumn{1}{c}{ Case, $(\%)$} & Control, $(\%)$ & $P$ value $^{\mathrm{a}}\left(\chi^{2}\right)$ & OR $(95 \%$ CI $)$ & $P$ value $^{\mathrm{b}}$ \\
\hline rs9470079 & GG & $85(59.9)$ & $23(37.7)$ & $0.014(8.540)^{*}$ & 1.00 & Referent \\
& GA & $58(40.8)$ & $31(50.8)$ & & $0.419(0.220-0.799)$ & $0.008^{*}$ \\
& AA & $9(6.3)$ & $7(11.5)$ & & $0.348(0.117-1.035)$ & 0.058 \\
& GA+AA & $57(47.1)$ & $38(62.3)$ & $0.004(8.412)^{*}$ & $0.406(0.219-0.752)$ & $0.004^{*}$ \\
& G & $210(73.9)$ & $77(63.1)$ & $0.009(6.804)^{*}$ & 1.00 & Referent \\
& A & $66(26.1)$ & $45(36.9)$ & & $0.545(0.344-0.862)$ & $0.010^{*}$ \\
\hline
\end{tabular}

\section{4}

5 Abbreviations: CI, confidence interval; OR, odds ratio.

$6 \quad{ }^{a} P$ value for genotype and allele frequencies in cases and controls using 2 -sided $\chi^{2}$ test.

$7 \quad$ b $P$ values adjusted by age and gender using logistic regression.

$8 * P<0.05$ 


\section{Table 5 (on next page)}

Table 5 Genotypic and allele Distribution of seven FKBP polymorphisms among the CAD with depression group, CAD without depression group and control group.

Abbreviations: $\mathrm{Cl}$, confidence interval; OR, odds ratio. ${ }^{\text {a }}$ vvalue for genotype and allele frequencies in cases and controls using 2-sided $\chi^{2}$ test.

${ }^{\mathrm{b}} P$ values adjusted by age and gender using logistic regression.

$* P<0.05$ 
1

2 Table 5 Genotypic and allele Distribution of seven FKBP polymorphisms among the CAD with 3 depression group, CAD without depression group and control group.

4

\begin{tabular}{|c|c|c|c|c|c|c|c|}
\hline & \multirow{2}{*}{ SNP } & \multirow{2}{*}{$\frac{1}{\mathrm{CAD}^{+} \mathrm{H}(\mathrm{n}=123)}$} & \multirow{2}{*}{$\frac{2}{\mathrm{CAD}^{-} \mathrm{H}(\mathrm{n}=147)}$} & \multirow{2}{*}{$\frac{3}{\text { Control }(n=113)}$} & \multicolumn{3}{|c|}{ P-value } \\
\hline & & & & & 1vs. 2 & $1 \mathrm{vs} .3$ & $2 \mathrm{vs} .3$ \\
\hline \multirow[t]{5}{*}{ rs 1360780} & $\mathrm{CC}$ & $60(48.8)$ & $74(50.3)$ & $60(53.1)$ & 0.968 & 0.650 & 0.739 \\
\hline & $\mathrm{CT}$ & $56(45.5)$ & $65(44.2)$ & $49(43.4)$ & & & \\
\hline & $\mathrm{TT}$ & $7(5.7)$ & $8(5.5)$ & $4(3.5)$ & & & \\
\hline & $\mathrm{C}$ & $176(48.8)$ & $213(48.8)$ & $169(48.8)$ & 0.816 & 0.429 & 0.551 \\
\hline & $\mathrm{T}$ & $70(48.8)$ & $81(48.8)$ & $57(48.8)$ & & & \\
\hline \multirow[t]{5}{*}{ rs2817032 } & $\mathrm{TT}$ & $63(51.2)$ & $79(53.7)$ & $69(61.1)$ & 0.733 & 0.301 & 0.334 \\
\hline & $\mathrm{TC}$ & $52(42.3)$ & $56(38.1)$ & $39(34.5)$ & & & \\
\hline & $\mathrm{CC}$ & $8(6.5)$ & $12(8.2)$ & $5(4.4)$ & & & \\
\hline & $\mathrm{T}$ & $178(48.8)$ & $214(48.8)$ & $177(48.8)$ & 0.991 & 0.134 & 0.148 \\
\hline & $\mathrm{C}$ & $68(48.8)$ & $80(48.8)$ & $49(48.8)$ & & & \\
\hline \multirow[t]{5}{*}{ rs 2817035} & GG & $52(42.3)$ & $67(45.6)$ & $61(54.0)$ & 0.665 & $0.021 *$ & 0.098 \\
\hline & GA & $65(52.8)$ & $75(51.0)$ & $52(46.0)$ & & & \\
\hline & $\mathrm{AA}$ & $6(4.9)$ & $5(3.4)$ & $0(0.0)$ & & & \\
\hline & G & $169(48.8)$ & $209(48.8)$ & $174(48.8)$ & 0.546 & $0.043 *$ & 0.130 \\
\hline & A & $77(48.8)$ & $85(48.8)$ & $52(48.8)$ & & & \\
\hline \multirow[t]{5}{*}{ rs9296158 } & GG & $53(43.1)$ & $59(40.1)$ & $47(41.6)$ & 0.590 & 0.903 & 0.865 \\
\hline & GA & $56(45.5)$ & $65(44.2)$ & $51(45.1)$ & & & \\
\hline & AA & $14(11.4)$ & $23(15.7)$ & $15(13.3)$ & & & \\
\hline & G & $162(48.8)$ & $183(48.8)$ & $145(48.8)$ & 0.385 & 0.700 & 0.654 \\
\hline & A & $84(48.8)$ & $111(48.8)$ & $81(48.8)$ & & & \\
\hline \multirow[t]{5}{*}{ rs9470079 } & GG & $71(57.7)$ & $75(51.0)$ & $42(37.2)$ & 0.462 & $0.006^{*}$ & 0.083 \\
\hline & GA & $44(35.8)$ & $58(39.5)$ & $58(51.3)$ & & & \\
\hline & $\mathrm{AA}$ & $8(6.5)$ & $14(9.5)$ & $13(11.5)$ & & & \\
\hline & G & $186(48.8)$ & $208(48.8)$ & $142(48.8)$ & 0.205 & $0.003 *$ & 0.056 \\
\hline & A & $60(48.8)$ & $86(48.8)$ & $84(48.8)$ & & & \\
\hline \multirow[t]{5}{*}{ rs4713902 } & $\mathrm{TT}$ & $62(50.4)$ & $83(56.5)$ & $73(64.6)$ & 0.140 & 0.088 & 0.139 \\
\hline & $\mathrm{TC}$ & $50(40.7)$ & $59(40.1)$ & $33(29.2)$ & & & \\
\hline & $\mathrm{CC}$ & $11(8.9)$ & $5(3.4)$ & $7(6.2)$ & & & \\
\hline & $\mathrm{T}$ & $174(48.8)$ & $225(48.8)$ & $179(48.8)$ & 0.127 & $0.034^{*}$ & 0.468 \\
\hline & $\mathrm{C}$ & $72(48.8)$ & $69(48.8)$ & $47(48.8)$ & & & \\
\hline \multirow[t]{5}{*}{ rs 3800373} & $\mathrm{CC}$ & $35(28.5)$ & $37(25.2)$ & $36(31.9)$ & 0.702 & 0.773 & 0.302 \\
\hline & $\mathrm{CA}$ & $82(66.7)$ & $100(68.0)$ & $73(64.6)$ & & & \\
\hline & $\mathrm{AA}$ & $6(4.8)$ & $10(6.8)$ & $4(3.5)$ & & & \\
\hline & $\mathrm{C}$ & $152(48.8)$ & $174(48.8)$ & $145(48.8)$ & 0.538 & 0.594 & 0.248 \\
\hline & A & $94(48.8)$ & $120(48.8)$ & $81(48.8)$ & & & \\
\hline
\end{tabular}


5 CAD+D: CAD with depression, CAD-D: CAD without depression

$6 * P<0.05$

7 


\section{Table 6(on next page)}

Table 6 Genotypic and Allelic Distribution of FKBP5 ( rs9470079) polymorphisms among the three studied groups between different genders.

CAD+D: CAD with depression, CAD-D: CAD without depression

$* P<0.05$ 
1 Table 6 Genotypic and Allelic Distribution of FKBP5 (rs9470079) polymorphisms among the 2 three studied groups between different genders.

\begin{tabular}{|c|c|c|c|c|c|c|c|}
\hline & \multirow{2}{*}{ SNP } & \multirow{2}{*}{$\frac{1}{\mathrm{CAD}^{+} \mathrm{H}}$} & \multirow{2}{*}{$\frac{2}{\mathrm{CAD}^{-} \mathrm{H}}$} & \multirow{2}{*}{$\frac{3}{\text { Control }}$} & \multicolumn{3}{|c|}{ P-value } \\
\hline & & & & & 1vs. 2 & 1vs.3 & $2 \mathrm{vs} .3$ \\
\hline \multirow[t]{6}{*}{ Males } & & $\mathrm{n}=53$ & $\mathrm{n}=75$ & $\mathrm{n}=52$ & & & \\
\hline & GG & $29(54.7)$ & $32(42.7)$ & $19(36.5)$ & 0.236 & 0.148 & 0.679 \\
\hline & GA & $21(39.6)$ & $33(44.0)$ & $27(52.0)$ & & & \\
\hline & $\mathrm{AA}$ & $3(5.7)$ & $10(13.3)$ & $6(11.5)$ & & & \\
\hline & G & $79(74.5)$ & $97(64.7)$ & $65(62.5)$ & 0.094 & 0.060 & 0.724 \\
\hline & A & $27(25.5)$ & $53(35.3)$ & $39(37.5)$ & & & \\
\hline \multirow[t]{6}{*}{ Females } & & $\mathrm{n}=70$ & $\mathrm{n}=72$ & $\mathrm{n}=61$ & & & \\
\hline & GG & $42(60.0)$ & $43(59.7)$ & $23(37.7)$ & 0.975 & $0.039 *$ & $0.036^{*}$ \\
\hline & GA & $23(32.9)$ & $25(34.7)$ & $31(50.8)$ & & & \\
\hline & $\mathrm{AA}$ & $5(7.1)$ & $4(5.6)$ & 7 (11.5) & & & \\
\hline & G & $107(76.4)$ & $111(77.1)$ & $77(63.1)$ & 0.896 & $0.019 *$ & $0.013^{*}$ \\
\hline & A & $33(23.6)$ & $33(22.9)$ & $45(36.9)$ & & & \\
\hline
\end{tabular}

3

4 CAD+D: CAD with depression, CAD-D: CAD without depression $5 * P<0.05$ 